\title{
Incidência da doença de Petri na videira 'Niagara Rosada’ no estado de São Paulo - Brasil
}

\author{
Ana Beatriz Monteiro Ferreira ${ }^{1,2}$, Luís Garrigós Leite ${ }^{1}$, Ricardo Harakava ${ }^{3}$, Carlos Roberto Padovani ${ }^{4}$, César Júnior \\ Bueno $^{1, *}$
}

${ }^{1}$ Instituto Biológico / APTA. Alameda dos Vidoeiros, n. 1097, Bairro Gramado, CEP 13101-680, Campinas - SP - Brasil; ${ }^{2}$ Bolsista CAPES (Parte da dissertação de mestrado); ${ }^{3}$ Instituto Biológico / APTA. Avenida Conselheiro Rodrigues Alves, 1252, CEP 04014-900, São Paulo - SP - Brasil; ${ }^{4}$ Instituto de Biociências / UNESP, CEP 18618-970, Botucatu - SP - Brasil.

*Autor para correspondência: César Júnior Bueno (cjbueno@biologico.sp.gov.br)

Data de chegada: 19/02/2016. Aceito para publicação em: 06/12/2017.

$10.1590 / 0100-5405 / 2154$

\section{RESUMO}

Ferreira, A.B.M.; Leite, L.G.; Harakava, R.; Padovani, C.R.; Bueno, C.J. Incidência da doença de Petri na videira 'Niagara Rosada' no estado de São Paulo - Brasil. Summa Phytopathologica, v.43, n.2, p.124-132, 2017.

A doença de Petri causada, principalmente, por Phaeomoniella chlamydospora e espécies de Phaeoacremonium é grave, complexa, ataca plantas jovens de videira e é de difícil controle no mundo. No Brasil, o estado de São Paulo está entre os maiores produtores da uva 'Niagara Rosada' e não há relato oficial desta doença no estado. Assim, os objetivos do presente trabalho foram avaliar a incidência da doença de Petri na videira 'Niagara Rosada' no estado de São Paulo e comparar metodologias para isolar os agentes causais da doença. O delineamento foi inteiramente casualizado, testando-se três meios de isolamento [ágar-água (AA), batata dextrose ágar (BDA) e isca de maçã-verde], com amostras de plantas doentes desinfestadas ou não, nove localidades de coleta e oito repetições (placa de Petri com os meios e quatro fragmentos das plantas por amostra). Anotou-se o número de colônias dos agentes causais por fragmento por placa de cada meio de cultura por localidade. Identificaram-se os isolados dos fungos obtidos por extração de DNA e sequenciamento da região ITS-5.8S do rDNA [ITS1 TCCGTAGGTGAACCTGCGG e ITS4 TCCTCCGCTTATTGATATGC] e partes dos genes da alfa elongase [EF1 ATGGGTAAGGARGACAAGAC e EF2 GGARGTACCAGTSATCATGTT] e da beta tubulina [Bt2a GGTAACCAAATCGGTGCTGCTTTC e Bt2b ACCCTCAGTGTAGTGACCCTTGGC]. Teste de patogenicidade foi feito com um isolado de Phaeomoniella spp. e um de Phaeoacremonium spp. A incidência e a severidade da doença (comprimento das estrias escuras no sistema vascular) foram avaliadas. Os municípios de Louveira B, Vinhedo, Jundiaí, Jarinú, Porto Feliz, São Miguel Arcanjo e Jales foram os que apresentaram a presença dos agentes causais da doença, demonstrando ocorrência da doença de Petri em todo o estado de São Paulo. A espécie de Phaeoacremonium prevalente foi $P$. minimum ( $=$ P. aleophilum). Somente na cidade de Jales, além de $P$. minimum detectou-se, também, a espécie $P$. venezuelense. Phaeomoniella chlamydospora foi a única espécie identificada neste gênero. A porcentagem de isolamento foi maior para $P$. chlamydospora do que para Phaeoacremonium spp. O isolamento dos agentes causais da doença deve ser feito retirando fragmentos do sistema vascular da região do colo das plantas sintomáticas seguido de desinfestação superficial e plaqueamento de fragmentos em meio de cultura BDA. Incuba-se em $\mathrm{BOD}$, a $23^{\circ} \mathrm{C}$, por até 21 dias. O método de isca e depois repicagem para BDA não permitiu isolar nenhum dos agentes causais da doença. Todas as plantas inoculadas desenvolveram sintomas externos e internamente a média do comprimento das estrias escuras para $P$. chlamydospora foi de $7,9 \mathrm{~cm}$ e de $P$. minimum foi de $5,2 \mathrm{~cm}$. As plantas controle (testemunha) permaneceram sadias. Os fungos foram re-isolados das plantas doentes, completando os postulados de Koch e oficializando a doença de Petri na videira 'Niagara Rosada' no estado de São Paulo - Brasil.

Palavras-chave: Phaeomoniella chlamydospora, Phaeoacremonium aleophilium, Phaeoacremonium minimum, declínio.

\section{ABSTRACT}

Ferreira, A.B.M.; Leite, L.G.; Harakava, R.; Padovani, C.R.; Bueno, C.J. Incidence of Petri disease in 'Niagara Rosada' grapevine in São Paulo State - Brazil.Summa Phytopathologica, v.43, n.2, p.124-132, 2017.

The Petri disease caused mainly by Phaeomoniella chlamydospora and species of Phaeoacremonium is serious, complex, attacks young vine plants and is difficult to be controlled worldwide. In Brazil, São Paulo State is among the largest producers of 'Niagara Rosada' grapevine, and there is no official report of this disease in the state. Thus, the aims of the present study were to evaluate the incidence of Petri disease in 'Niagara Rosada' grapevine in São Paulo State and to compare methodologies to isolate the causal agents of this disease. Experimental design was completely randomized, testing three culture media (water-agar [WA], potato dextrose agar [PDA] and apple-green bait) with samples of diseased plants, disinfested or not, from nine sampling locality and eight replicates (Petri dish with the media and four fragments of the plants per sample). The number of colonies of causal agents per fragment per dish of each culture medium per locality was determined. Fungal isolates obtained by DNA extraction and sequencing of ITS-5.8S rDNA region [ITS1 TCCGTAGGTGAACCTGCGG and ITS4 TCCTCCGCTTATTGATATGC] and parts of the alpha elongase genes [EF1 ATGGGTAAGGARGACAAGAC and EF2 GGARGTACCAGTSATCATGTT] and beta tubulin genes [Bt2a GGTAACCAAATCGGTGCTGCTTTC and Bt2b ACCCTCAGTGTAGTGACCCTTGGC] were identified. Pathogenicity test was done with one isolate of Phaeomoniella spp. and one isolate of Phaeoacremonium spp. The disease incidence and severity (length of dark streaks in the vascular system) were evaluated. The municipalities Louveira B, Vinhedo, Jundiaí, Jarinu, Porto Feliz, Sao Miguel Arcanjo and Jales were the localities where the causal agents of the disease were present, demonstrating that the Petri disease occurs throughout São Paulo State. The most prevalent species of Phaeoacremonium was P. minimum (= P. aleophilum). Besides $P$. minimum, the species $P$. venezuelense was detected only in the municipality of Jales. P. chlamydospora was the only species identified within this genus. Isolation percentage was higher for $P$. chlamydospora than for Phaeoacremonium spp. The causal agents of the disease must be isolated by removing fragments of the vascular system from the collar region of symptomatic plants, followed by surface disinfection and plating of fragments in PDA culture medium. Incubation in BOD should be at $23^{\circ} \mathrm{C}$ for up to 21 days. The apple-green bait method followed by culturing in PDA did not allow isolation of any of the causal agents of the disease. All inoculated plants developed external symptoms and internally the average length of dark streaks was $7.9 \mathrm{~cm}$ for $P$. chlamydospora and $5.2 \mathrm{~cm}$ for $P$. minimum. Control plants remained healthy. Fungi were re-isolated from diseased plants, completing the Koch's postulates, thus making official the record of Petri disease in 'Niagara Rosada' grapevine in São Paulo State, Brazil.

Keywords: Phaeomoniella chlamydospora, Phaeoacremonium aleophilium, Phaeoacremonium minimum, decline. 
No Brasil, a viticultura tem se tornado uma atividade importante na sustentabilidade da pequena propriedade. A uva é cultivada, principalmente, com as seguintes finalidades: produção de sucos e fermentados (vinho), consumo "in natura" ou como uva passa. Recentemente, tem-se desenvolvido o turismo voltado a esta cultura $(5,7,10)$.

O estado de São Paulo está entre os maiores produtores brasileiro de uva de mesa, principalmente com a cultivar 'Niagara Rosada'. A produção desta uva está concentrada nas regiões leste e sudoeste do estado, abrangendo os municípios de Jundiaí, Vinhedo, Louveira, Indaiatuba, Sorocaba, Porto Feliz e São Miguel do Arcanjo, e, também, em Jales, região norte do estado. A cultivar 'Niagara Rosada' é resultado de uma mutação somática ocorrida na videira 'Niagara Branca' (Vitis labrusca L. x Vitis vinifera L.) em 1933, em Louveira, São Paulo / Brasil, predominando sobre a forma original $(29,32)$

Dentre as doenças fúngicas de solo na cultura da videira, destacase a doença de Petri. Essa doença foi relatada pela primeira vez no início do século XX, na Sicília, Itália (27), sendo considerada doença grave em videira, porque é complexa e de difícil controle. É causada, principalmente, pelo fungo Phaeomoniella chlamydospora e várias espécies de Phaeoacremonium (30). Phaeomoniella chlamydospora tem sido muito mais associado aos sintomas típicos da doença do que às espécies de Phaeoacremonium (25). Dentre as espécies de Phaeoacremonium, $P$. minimum ( $=P$. aleophilum) é a mais amplamente distribuída e mais comum em videiras $(20,24)$.

Segundo Gatica et al. (15) e Mostert et al. (24), a doença de Petri ocorre, predominantemente, em vinhedos jovens. A sintomatologia da doença consiste no desenvolvimento inicial comprometido e no reduzido vigor vegetativo seguidos de interrupção de crescimento e morte de planta (declínio). Plantas afetadas revelam ainda menor diâmetro do tronco, encurtamento de internódios, reduzidas quantidades de folhagem e de área foliar. Os sintomas foliares, desenvolvidos de três a cinco anos após o transplantio, incluem cloroses internervais, necroses das extremidades e murchas, que podem resultar em desfolha prematura. Quando observados em seção transversal, os vasos do xilema do colo da planta (parte de baixo do porta-enxerto) apresentam pontos de cor negra ou marrom escuros. Em seção longitudinal, os elementos de vaso mostram estrias escurecidas. Essas estrias de vasos obstruídos ocorrem próximas à medula, que também pode estar afetada e escurecida (3). Na parte interna, é possível observar o escurecimento de vasos do xilema com produção associada de tiloses de massas de goma escura, o que resulta em oclusão de elementos traqueais. Os fungos da doença podem ser isolados a partir de tecido lenhoso próximo aos elementos traqueais obstruídos, e a forma como esses patógenos habitam a região do apoplasto do tecido vascular vai depender do potencial hídrico do tecido naquele ponto, uma vez que os patógenos dependem do hospedeiro para obter água e nutrientes (6). Os sintomas podem ser agravados durante a fase patogênica, caso as plantas estejam submetidas a estresses diversos, em particular o estresse hídrico. O bloqueio de vasos do xilema no processo de infecção acentua, ainda mais, a restrição hídrica da copa, levando à diminuição no fornecimento de água e nutrientes para as partes vegetativas, o que agrava os sintomas, durante o período de maior demanda por água. Outros fatores relacionados ao ambiente, como o desequilíbrio nutricional, a má drenagem, a compactação do solo, o preparo inadequado do solo e da cova para o plantio, podem contribuir para o aumento da incidência da doença (19).

A doença de Petri vem sendo encontrada em várias partes do mundo onde se cultiva videira $(3,9,15)$. No Brasil, a doença foi constatada pela primeira vez no Rio Grande do Sul $(2,14)$ e, posteriormente, no Nordeste (8). No estado de São Paulo, um dos maiores produtores de 'Niagara Rosada' (29), não há relatos desta doença.

Assim, os objetivos do presente trabalho foram avaliar a incidência da doença de Petri em cultivos da uva 'Niagara Rosada' no estado de São Paulo - Brasil e comparar métodos para se isolar os principais agentes causais desta doença.

\section{MATERIAL E MÉTODOS}

\section{Coleta de plantas de videira e processamento}

Três plantas jovens (3-5 anos) de videira da cultivar 'Niagara Rosada', apresentando alguns dos sintomas típicos da doença de Petri $(3,6)$, foram coletadas, ao acaso, em propriedade vinícola nas seguintes localidades: Louveira A $\left(23^{\circ} 06.716^{\prime} \mathrm{S}\right.$ e $\left.46^{\circ} 54.857^{\prime} \mathrm{W}\right)$, Louveira B ( $23^{\circ} 05.800^{\prime} \mathrm{S}$ e $\left.46^{\circ} 55.625^{\prime} \mathrm{W}\right)$, Vinhedo $\left(23^{\circ} 02.430^{\prime} \mathrm{S}\right.$ e $\left.46^{\circ} 58.886^{\prime} \mathrm{W}\right)$, Jundiaí $\left(23^{\circ} 07.830^{\prime} \mathrm{S}\right.$ e $\left.46^{\circ} 56.853^{\prime} \mathrm{W}\right)$, Indaiatuba $\left(23^{\circ} 07.958^{\prime} \mathrm{S}\right.$ e $\left.47^{\circ} 09.538^{\prime} \mathrm{W}\right)$, Jarinú $\left(23^{\circ} 07.761^{\prime} \mathrm{S}\right.$ e $46^{\circ} 40.951^{\prime}$ W), Porto Feliz ( $23^{\circ} 17.546^{\prime}$ S e $47^{\circ} 28.252^{\prime}$ W), São Miguel Arcanjo $\left(23^{\circ} 49.750^{\prime}\right.$ S e $47^{\circ} 59.008^{\prime} \mathrm{W}$ ) e Jales (20 $12.376^{\prime} \mathrm{S}$ e $\left.50^{\circ} 36.190^{\prime} \mathrm{W}\right)$.

Uma amostra do sistema vascular da região do colo das plantas, mais precisamente do porta-enxerto, foi retirada das três plantas e, em seguida, esse material foi subdividido, sendo que metade das amostras permaneceram intactas enquanto a outra metade foi submetida ao processo de desinfestação superficial modificado de Pinto (28) (30 segundos em solução de álcool a 70\%; 1 minuto em solução de hipoclorito de sódio a 1,5\%, seguido de uma imersão em água destilada esterilizada e secagem em papel de filtro estéril). Após isso, as duas amostras individualmente foram cortadas em fragmentos menores e misturadas, resultando em duas amostras compostas, para cada localidade. O material de cada amostra composta foi plaqueado em três meios de cultura diferentes.

\section{Meios de isolamento de patógenos da doença de Petri e delineamento experimental}

Os meios de cultura para o plaqueamento foram o ágar-água (AA), batata dextrose ágar (BDA) e isca de maçã-verde. Para a maçã-verde, fragmentos de maçã foram cortados e, em seguida, ficaram por cinco minutos em solução de hipoclorito de sódio a 1,5\% para desinfestação superficial. Nessa metodologia desenvolvida, as iscas foram colocadas sob lâminas de vidro e este conjunto ficou no interior de placas de Petri de vidro contendo papel de filtro. Todo o conjunto foi previamente esterilizado. Os fragmentos do sistema vascular das plantas que resultaram na amostra composta e que foram desinfestados ou não, ficaram, portanto, em um sanduíche de pedaços de maçã-verde nas placas de vidro. O papel de filtro estéril nas placas de Petri foi umedecido com água destilada esterilizada com o intuito de formar câmara úmida e facilitar a germinação de eventuais estruturas de fungos presente nos fragmentos do sistema vascular das plantas.

Em cada placa de Petri, contendo um dos meios em teste, foram colocados quatro fragmentos, desinfestados ou não, retirados ao acaso da amostra composta de cada planta. Em seguida, os meios foram mantidos em estufa tipo BOD, a $23^{\circ} \mathrm{C}$, com fotoperíodo de 12 horas, por até 21 dias.

Nos tratamentos envolvendo iscas de maçã-verde, todos os fragmentos de maçã, após sete dias incubados em contato com o fragmento da planta, foram transferidos para placas de Petri contendo BDA. Nos tratamentos com o meio agar-água, após sete dias de incubação, colônias de fungos crescidas a partir dos fragmentos de 
planta foram repicados para placas contendo BDA. Em ambos os casos, as placas foram mantidas em estufa por mais 14 dias.

O delineamento do ensaio foi o inteiramente casualizado, com três meios de isolamentos diferentes, com amostras de plantas doentes desinfestadas ou não, nove localidades de coleta e oito repetições, sendo cada repetição representada por uma placa de Petri com os meios e quatro fragmentos das plantas por amostra.

\section{Forma de avaliação e análise estatística}

Anotou-se o número de colônias características dos agentes causais da doença de Petri, crescidas em cada placa de Petri.

Considerou-se resultado positivo de incidência da doença de Petri na localidade, se um único fragmento da planta, dos 192 plaqueados por localidade, apresentasse crescimento do agente causal da doença.

Para determinar a melhor metodologia (meio de cultura e processo de desinfestação) para isolar os agentes causais da doença de Petri, aplicou-se o teste de associação de Goodman $(17,18)$ envolvendo contrastes entre e dentro de populações binomiais (sucesso e fracasso de detecção dos agentes nas metodologias), considerando o nível de $5 \%$ de significância.

\section{Identificação molecular dos agentes causais da doença de Petri detectados}

Os isolados monospóricos dos fungos foram, primeiramente, identificados com base nos aspectos das colônias em meio de cultura e depois com base na morfologia do conidióforo e dos conídios, usando, principalmente, microscópio ótico com aumento de $400 \mathrm{x}$. Para cada grupo de espécie identificada, escolheu-se um isolado que apresentasse as características dos demais, para confirmação molecular da espécie. Para essa confirmação molecular, extraiu-se o DNA apenas de quatro isolados diferentes de fungos detectados em todo o levantamento, seguindo-se o método CTAB descrito por Doyle; Doyle (11). A reação em cadeia da polimerase (PCR) para a amplificação da região ITS-5.8S do rDNA foi realizada com os oligonucleotídeos iniciadores ITS1 (TCCGTAGGTGAACCTGCGG) e ITS4 (TCCTCCGCTTATTGATATGC) (34). Fragmento do gene codificador da subunidade alfa do complexo do fator de elongação 1 (EF) foi amplificado com o par de primers EF1 (ATGGGTAAGGARGACAAGAC) e EF2 (GGARGTACCAGTSATCATGTT) (26), e fragmento do gene codificador da beta tubulina ( $\beta$ Tubulin) com o par de primers Bt2a (GGTAACCAAATCGGTGCTGCTTTC) e Bt2b (ACCCTCAGTGTAGTGACCCTTGGC) de Glass e Donaldson (16). As reações foram efetuadas em termociclador PTC100 (MJ Research) seguindo-se a seguinte programação: desnaturação inicial a $94^{\circ} \mathrm{C} / 2 \mathrm{~min}, 40$ ciclos de $94^{\circ} \mathrm{C} / 30 \mathrm{~s}-54^{\circ} \mathrm{C} / 30 \mathrm{~s}-72^{\circ} \mathrm{C} / 60 \mathrm{~s}$, extensão final a $72^{\circ} \mathrm{C} / 4 \mathrm{~min}$. Os produtos de PCR foram purificados por precipitação com polietilenoglicol, segundo protocolo descrito por Schmitz; Riesner (31). O sequenciamento foi realizado pelo método de terminação de cadeia com o reagente BigDye 3.1 (Applied Biosystems) e sequenciador automático ABI3500 XL (Applied Biosystems). Após o sequenciamento, construíram-se as árvores filogenéticas com sequência dos isolados, mais sequências de diferentes gêneros de fungos incidentes em videira, obtidos do GENBANK/NCBI.

O alinhamento de nucleotídeos foi realizado através do programa MUSCLE (12). As árvores filogenéticas foram construídas pelo método de Neighbor Joining empregando-se o programa MEGA 6 (33) com avaliação da reprodutibilidade da topologia através de bootstrap com 1000 repetições. O valor de suporte obtido para cada ramificação da árvore está apresentado na Figura 1, não tendo sido adotado um valor mínimo para separação dos ramos.

Teste de patogenicidade de fitopatógenos da doença de Petri obtidos

Um isolado de Phaeoacremonium spp. (IBVD 05) e um de Phaeomoniella spp. (IBVD 01) foram escolhidos para realização do teste de patogenicidade com o intuito de comprovar a patogenicidade dos mesmos em plantas comprovadamente sadias de 'Niagara Rosada' e com isso relatar, oficialmente, a incidência da doença de Petri.

A produção de inóculo dos fungos foi feita em placas de Petri contendo o meio de cultura batata-dextrose-ágar (BDA) + oxitetraciclina $(0,05 \mathrm{mg} / \mathrm{mL})$, incubando-se os fungos, separadamente, em câmara de crescimento a $23^{\circ} \mathrm{C}$, com fotoperíodo de 12 horas, por 21 dias. A inoculação dos fungos nas plantas foi realizada através da deposição de disco de BDA colonizado pelo fungo $(0,5 \mathrm{~cm}$ de diâmetro), em ferimento circular realizado no colo das plantas $(0,5 \mathrm{~cm}$ de diâmetro), com auxílio de vazador metálico. Em seguida, o local de inoculação foi selado com gaze umedecida em água destilada e parafilme (13). No tratamento controle, plantas receberam disco de BDA, sem o fungo.

O delineamento do ensaio foi o inteiramente casualizado com três tratamentos (inoculado com Phaeomoniella spp. e Phaeoacremonium spp. e não inoculado) e 10 repetições, sendo cada repetição representada por uma muda de 'Niagara Rosada', plantada em saquinho, com solo solarizado. As plantas foram regadas diariamente e mantidas em casa-de-vegetação por quatro meses, sem controle de temperatura (28). Os parâmetros avaliados foram: a) incidência número de plantas com sintomas externos da doença; b) severidade da doença - medição do crescimento do fungo $(\mathrm{cm})$ no sistema vascular (estrias escuras) das plantas, a partir do ponto de inoculação (colo) em direção ao sistema radicular. Os dados de severidade da doença foram transformados em $\sqrt{x}+0,5$ e analisados pelo teste de Scott-Knott com $5 \%$ de probabilidade.

Os fungos foram reisolados das plantas sintomáticas, com o intuito de se completarem os postulados de Koch.

\section{RESULTADOS E DISCUSSÃO}

Os agentes causais da doença de Petri foram encontrados nas plantas da videira 'Niagara Rosada' amostradas de todos os municípios paulistas visitados, exceto de Louveira A e Indaiatuba (Tabela 1). Isso caracteriza a disseminação destes agentes em todo o estado de São Paulo nos cultivos comerciais da videira 'Niagara Rosada'.

Os porta-enxertos IAC 766 e IAC 572, Ripária do Traviú e Ripária Gloire, os mais utilizados dentro do estado para 'Niagara Rosada', mostraram-se suscetíveis a Phaeoacremonium spp. e Phaeomoniella spp. (Tabela 1), reforçando a necessidade de pesquisas para buscar algum porta-enxerto com alguma resistência aos fitopatógenos citados e, também, pesquisas para estabelecer métodos de desinfecção dos porta-enxertos infectados, visando a obtenção de mudas sadias.

Em todo o levantamento realizado apenas quatro espécies diferentes dos agentes causais da doença de Petri foram detectadas. Do município de Jundiaí, retirou-se um isolado típico de Phaeomoniella spp. (IBVD 01) detectado em muitas localidades e dois isolados de Phaeoacremonium spp. (IBVD 04 e IBVD 05). O isolado IBVD 05 foi detectado em todas as localidades visitadas. Além dos dois isolados de Phaeoacremonium (IBVD 04 e IBVD 05), mais um isolado deste gênero foi encontrado no município de Jales (IBVD 03). 
Tabela 1. Incidência de Phaeoacremonium spp. e / ou Phaeomoniella spp. na videira 'Niagara Rosada' enxertada em diferentes porta-enxertos, em nove municípios do estado de São Paulo - Brasil.

\begin{tabular}{lccc}
\hline Municípios & Porta-enxertos & Phaeoacremonium spp. & Phaeomoniella spp. \\
\hline Louveira A & IAC 766 & $-^{-1}(0 / 192)^{2}$ & $-(0 / 192)$ \\
Louveira B & IAC 572 & $+(2 / 192)$ & $+(5 / 192)$ \\
Vinhedo & IAC 766 & $-(0 / 192)$ & $+(25 / 192)$ \\
Jundiaí & Ripária do Traviú & $+(2 / 192)$ & $+(35 / 192)$ \\
Indaiatuba & Ripária Gloire & $-(0 / 192)$ & $-(0 / 192)$ \\
Jarinú & IAC 766 & $+(13 / 192)$ & $+(5 / 192)$ \\
Porto Feliz & Ripária Gloire & $+(6 / 192)$ & $+(23 / 192)$ \\
São Miguel Arcanjo & Ripária do Traviú & $+(8 / 192)$ & $-(0 / 192)$ \\
Jales & IAC 572 & $+(20 / 192)$ & $-(0 / 192)$ \\
\hline
\end{tabular}

${ }^{1}+=$ detecção dos agentes causais na videira do município; - = não deteç̧ão dos agentes causais na videira do município. ${ }^{2}$ número de fragmentos com crescimento do agente causal pelo número total de fragmentos plaqueados.

De acordo com as árvores filogenéticas construídas (Figura 1), em todas as localidades onde se detectou Phaeoacremonium spp., a espécie prevalente foi P. minimum (IBVD 05). Em Jundiaí, detectou-se um isolado de P. minimum (IBVD 04) que apresentou aspectos da colônia diferentes em relação ao isolado de $P$. minimum (IBVD 05) sobre o meio de cultura (dados não apresentados), com pequenas diferenças também na região ITS e nos genes EF e beta tubulina (Figura 1). Devido à alta variabilidade da região ITS e dos introns dos genes EF e beta tubulina, pequenas diferenças intraespecíficas podem ser observadas nessas sequências.

De acordo com os resultados obtidos no presente estudo e em conformidade com os trabalhos de Mostert et al. (24) e Gramaje et al. (20), dentre as espécies de Phaeoacremonium, $P$. minimum $(=P$. aleophilum) é a mais amplamente distribuída e a mais comum em videiras.

No município de Jales, além de $P$. minimum detectou-se, também, a espécie P. venezuelense (IBVD 03) (Figura 1). Segundo Mostert et al. (24), P. venezuelense ocorre em Vitis vinifera e, também, em humanos.

Nas localidades onde se detectou Phaeomoniella spp., a única espécie identificada foi P. chlamydospora (Figura 1). Crous \& Gams (9) relataram ocorrência de $P$. chlamydospora apenas em Vitis vinifera na Argentina, Austrália, Chile, Europa, África do Sul, Califórnia (USA) e na Nova Zelândia. Recentemente, Agustí-Brisach et al. (4) detectaram ocorrência de P. chlamydospora na planta daninha Convolvulus arvensis, alterando sobremaneira a epidemiologia da doença de Petri.

Quanto a identificação molecular dos agentes causais da doença de Petri, Groenewald et al. (21) relataram que a região ITS não é suficientemente informativa para distinguir todas as espécies de Phaeoacremonium. Em conformidade com os relatos de Groenewald et al. (21) e comparando as árvores filogenéticas obtidas com as sequências da região ITS e dos genes do fator de elongação e da beta tubulina do presente estudo, as árvores construídas com os dois últimos genes, devido a sua maior variabilidade, permitiram uma melhor identificação dos isolados obtidos, principalmente daqueles identificados como P. minimum (Figura 1).

Para o fungo Phaeoacremonium spp. não houve diferença significativa entre as amostras desinfestadas ou não com a finalidade de isolamento e entre os meios BDA e de AA - BDA. Para $P$. chlamydospora, as amostras desinfestadas diferiram significativamente das não desinfestadas e os meios BDA e AA - BDA foram os melhores. $\mathrm{O}$ método de isca e depois repicagem para BDA não permitiu isolar nenhum dos agentes causais da doença de Petri. Quanto aos fungos, $P$. chlamydospora teve uma incidência maior que Phaeoacremonium spp. apenas nas amostras desinfestadas no meio AA - BDA (Tabela 2). Para fins prático de isolamento, recomenda-se desinfestar as amostras da região do colo das plantas e depois plaquear os fragmentos do sistema vascular desta região diretamente em meio de BDA.

Pinto (28) realizou vários estudos com $P$. chlamydospora, fazendo o isolamento deste fungo a partir de material vegetal, mediante desinfestação superficial com solução de álcool a 70\% e solução de hipoclorito de sódio a 7\% e lavagem do material em água destilada esterilizada seguido de secagem do mesmo em papel de filtro estéril. O plaqueamento do material desinfestado de Pinto (28) ocorreu em meio de BDA e as placas foram mantidas em estufa tipo BOD a $22^{\circ} \mathrm{C}$ por 15 dias. No presente estudo, os procedimentos de desinfestação dos materiais da videira 'Niagara Rosada', o uso do meio de BDA e a temperatura escolhida foram adaptadas com modificações do trabalho de Pinto (28).

A doença de Petri é causada, principalmente, por uma combinação ou não dos fungos $P$. chlamydospora e Phaeoacremonium spp. Destes fungos, $P$. chlamydospora tem sido muito mais associado a plantas com sintomas típicos da doença de Petri e, também, isolado com maior frequência $(23,24,25)$. Em concordância com outros estudos, $P$. chlamydospora ocorreu no presente estudo em frequência muito maior que Phaeoacremonium spp. (Tabelas 1 e 2).

No teste de patogenicidade, todas as plantas inoculadas com os patógenos apresentaram sintomas externos e internos. Plantas controle não apresentaram sintomas. Internamente, os fungos causaram estrias escuras no sistema vascular das plantas. O comprimento médio das estrias escuras (severidade da doença) causada por $P$. chlamydospora foi de $7,9 \mathrm{~cm}$ e este valor diferiu significativamente do comprimento médio das estrias causadas por P. minimum, que foi de 5,2 cm (Tabela 3 ). A maior agressividade de $P$. chlamydospora está de acordo com os relatos dos trabalhos de Halleen et al. $(22,23)$.

Dentre os sintomas externos nas plantas doentes, observou-se queda prematura de folhas e menor desenvolvimento das plantas (declínio). No tratamento controle, as plantas permaneceram sadias (Figura 2).

Os fungos do teste de patogenicidade foram reisolados das plantas 


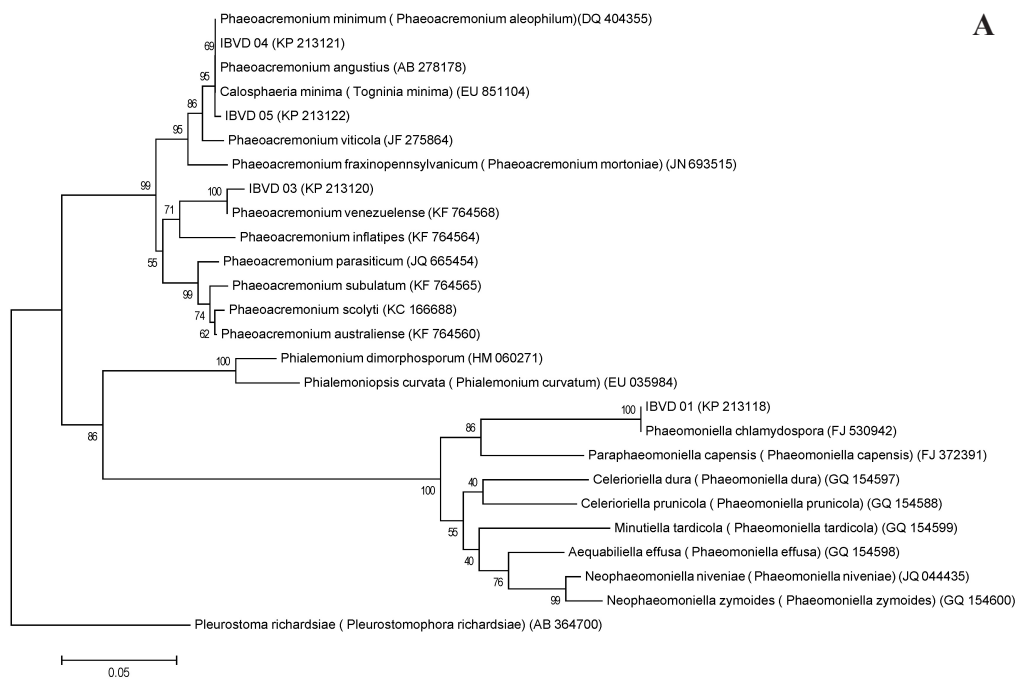

A
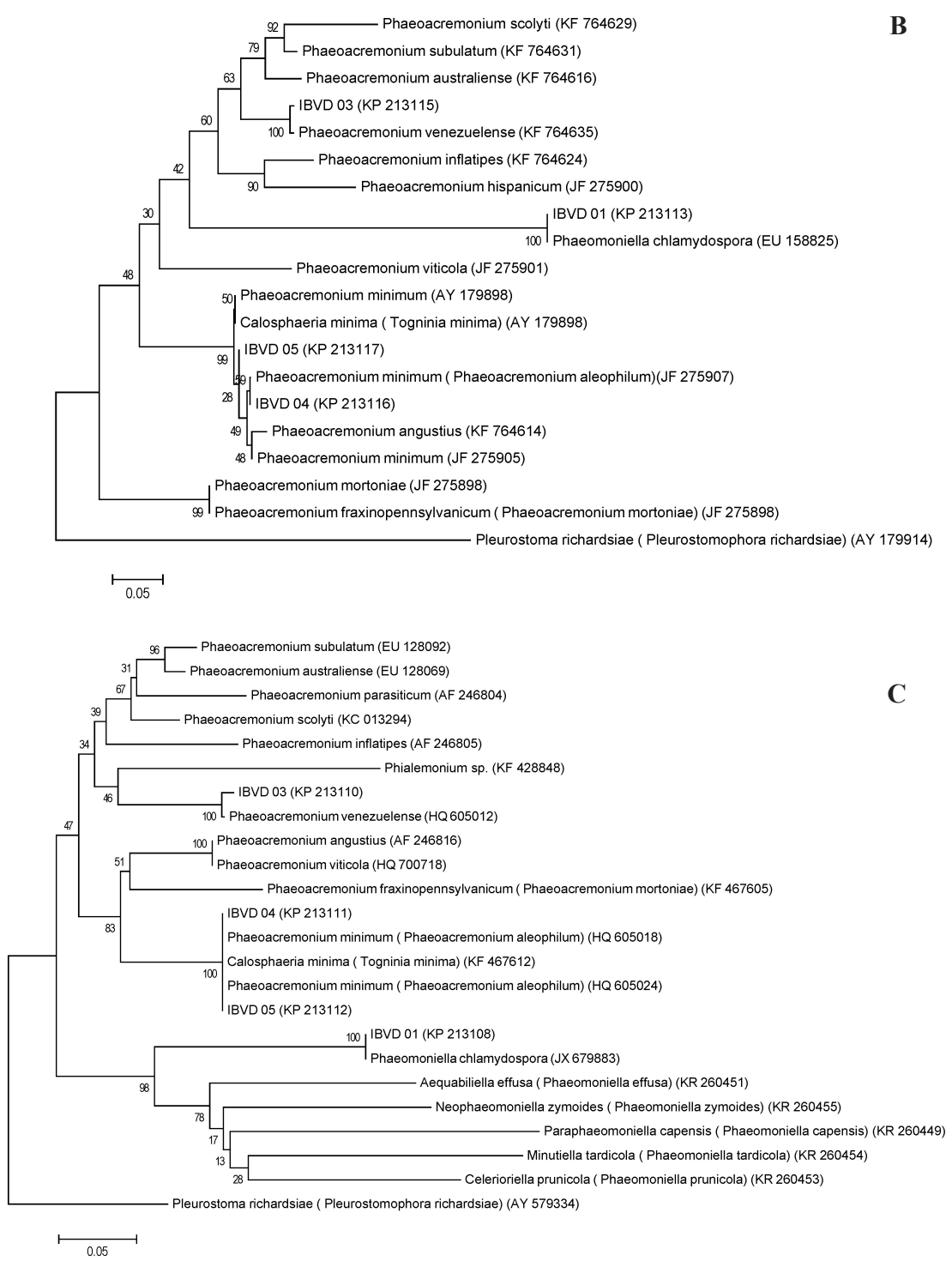

Figura 1. Árvores filogenéticas mostrando a relação entre os isolados de Phaeomoniella spp. e de Phaeoacremonium spp. obtidos no presente estudo com espécies de fungos de videira depositados no GenBank-NCBI. As árvores foram construídas com base nas seguintes sequências: A) região ITS-5.8S rDNA; B) partes do gene da alfa elongase e C) partes do gene da beta tubulina. O isolado Pleurostoma richardsiae (= Pleurostomophora richardsiae) foi utilizado como outgroup. O número de acesso das sequências dos isolados no GENBANK-NCBI consta entre parêntese. 
Tabela 2. Incidência de Phaeoacremonium spp. e de Phaeomoniella chlamydospora nas plantas da videira 'Niagara Rosada' amostradas em diferentes localidades visitadas, testando três meios de cultura diferentes e dois processos de desinfestação superficial para o isolamento dos fitopatógenos.

\begin{tabular}{|c|c|c|c|}
\hline Fitopatógeno & Desinfestação & Meio de cultura & Incidência \\
\hline \multirow{4}{*}{ Phaeoacremonium spp. } & \multirow{2}{*}{ Sim } & AA -- BDA & $8^{1}\left(11,1 \%{ }^{2}\right) b^{3} A^{4} \alpha^{5}$ \\
\hline & & ISCA & $0(0,0 \%)$ a $\mathrm{A} \alpha$ \\
\hline & \multirow[t]{2}{*}{ Não } & $\mathrm{BDA}$ & $12(16,7 \%)$ b A $\alpha$ \\
\hline & & ISCA & $0(0,0 \%)$ a $\mathrm{A} \alpha$ \\
\hline \multirow{5}{*}{ Phaeomoniella chlamydospora } & \multirow{2}{*}{ Sim } & AA -- BDA & $23(31,9 \%)$ b B $\beta$ \\
\hline & & ISCA & $0(0,0 \%)$ a $\mathrm{A} \alpha$ \\
\hline & \multirow{3}{*}{ Não } & AA -- BDA & $3(4,2 \%)$ a $\mathrm{A} \alpha$ \\
\hline & & $\mathrm{BDA}$ & $6(8,3 \%)$ a $\mathrm{A} \alpha$ \\
\hline & & ISCA & $0(0,0 \%)$ a $\mathrm{A} \alpha$ \\
\hline
\end{tabular}

${ }^{1}$ Incidência do fitopatógeno nas 72 repetições, sendo cada repetição uma placa de Petri contendo o meio de cultura e quatro fragmentos de plantas de videira de todos os municípios paulistas visitados passados ou não pelo processo de desinfestação; ${ }^{2}$ Porcentagem de incidência do fitopatógeno no método testado; ${ }^{3}$ Letras minúsculas comparam os diferentes meios de cultura, segundo o teste de Goodman $(17,18)$ com $5 \%$ de significância; ${ }^{4}$ Letras maiúsculas comparam os processos de desinfestação, segundo o teste de Goodman $(17,18)$ com $5 \%$ de significância; ${ }^{5}$ Letras gregas comparam os fitopatógenos, segundo o teste de Goodman $(17,18)$ com $5 \%$ de significância.

Tabela 3. Comprimento $(\mathrm{cm})$ de estrias escuras causadas por Phaeomoniella chlamydospora e Phaeoacremonium minimum no sistema vascular de mudas da videira 'Niagara Rosada' enxertadas no porta-enxerto IAC 766 e que ficaram mantidas em casa-de-vegetação por quatro meses.

\begin{tabular}{|c|c|c|c|}
\hline \multirow{2}{*}{ Planta } & \multicolumn{2}{|c|}{ Inoculação } & \multirow{2}{*}{ Controle } \\
\hline & Phaeomoniella chlamydospora & Phaeoacremonium minimum & \\
\hline 1 & 7,5 & 8,5 & 0,0 \\
\hline 3 & 9,5 & 9,3 & 0,0 \\
\hline 4 & 9,4 & 7 & 0,0 \\
\hline 6 & 1,0 & 3,2 & 0,0 \\
\hline 7 & 9,8 & 4,5 & 0,0 \\
\hline 8 & 10,0 & 1,8 & 0,0 \\
\hline 9 & 9,3 & 5,5 & 0,0 \\
\hline 10 & 6,3 & 2,7 & 0,0 \\
\hline
\end{tabular}

${ }^{1}$ Letras diferentes diferem entre si segundo o teste de Scott-Knott com $5 \%$ de probabilidade. CV $=25,1 \%$.

inoculadas, comprovando serem eles os agentes causais da doença e, também, oficializando a doença de Petri na videira 'Niagara Rosada' no estado de São Paulo.

Em função do relato de ocorrência $P$. venezuelense em humanos (24), não se realizou teste de patogenicidade com o isolado deste fungo obtido de 'Niagara Rosada' do município de Jales.

No Rio Grande do Sul - Brasil, Garrido et al. (14) detectaram o fungo Phaeoacremonium spp. na parte aérea de videiras americanas, incluindo na videira 'Niagara Rosada'. Em 2013, também no Rio Grande do Sul - Brasil, Almança et al. (2) isolaram o fungo $P$. chlamydospora de plantas de videira de cultivares americanas apresentando sintomas de morte e/ou declínio. Ainda no Brasil, nos estados de Pernambuco (Vale do São Francisco e Vale do Siriji) e no Rio Grande do Norte (Vale do Assú), Correia et al. (8) isolaram e identificaram molecularmente os seguintes fungos de plantas de videira com sintomas de declínio: Campylocarpon fasciculare, Campylocarpon pseudofasciculare, Fusicoccum atrovirens, Lasiodiplodia crassipora, Lasiodiplodia parva, Lasiodiplodia pseudotheobromae, Lasiodiplodia theobromae, Neofusicoccum parvum, Phaeoacremonium minimum (= Phaeoacremonium aleophilum), Phaeoacremonium parasiticum e Phaeomoniella chlamydospora. Em todos estes trabalhos $(2,8,14)$, os autores não fizeram o teste de patogenicidade tradicional com os fungos isolados, o que seria necessário para oficializar a incidência da doença no estado ou no município visitado. No mundo, diversos países já oficializaram a incidência da doença de Petri em suas regiões vinícolas $(1,3)$.

Conclui-se que a doença de Petri ocorre e está disseminada em todo o estado de São Paulo nos cultivos da videira 'Niagara Rosada'. A detecção da doença pode ser feita principalmente pela coleta de plantas jovens com os sintomas do declínio e retirada de fragmentos do sistema vascular da região do colo seguido de desinfestação superficial e plaqueamento dos fragmentos diretamente em meio de BDA. O material deve ser incubado em BOD a $23^{\circ} \mathrm{C}$ por até 21 dias. A porcentagem de isolamento dos agentes causais das plantas foi maior para P. chlamydospora do que para Phaeoacremonium 


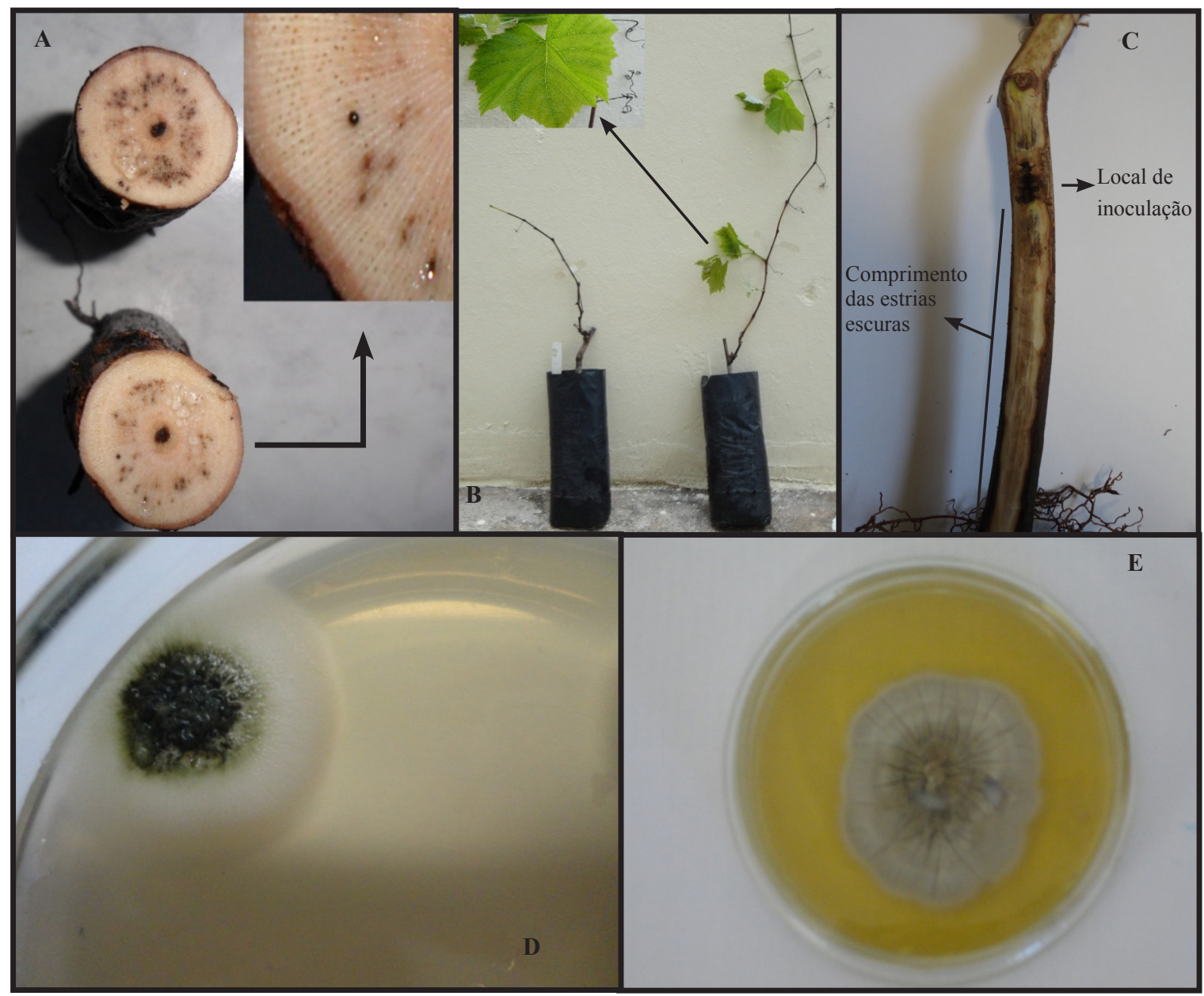

Figura 2. A = Corte transversal na região do colo do porta enxerto IAC 766 com três anos de idade mostrando pontos escuros no sistema vascular e detalhe da exsudação tipo "chocolate" causada pelo fungo Phaeoacremonium spp.; B = Detalhe de uma muda de 'Niagara Rosada' (à esquerda) enxertada no porta enxerto IAC 766, que foi inoculada com o fungo Phaeomoniella chlamydospora, exibindo sintomas da doença de Petri como desfolha e sub-desenvolvimento (declínio). À direita, a mesma muda sem ter sido inoculada, exibindo ausência de sintomas; $\mathrm{C}=\mathrm{Detalhe}$ das estrias escuras causadas pelo fungo P. chlamydospora no sistema vascular da planta, do local de inoculação (região do colo) em direção ao sistema radicular; Aspecto da colônia de P. chlamydospora (D) e de Phaeoacremonium spp. (E) no meio de cultura batata-dextrose-ágar (BDA).

spp., prevalecendo as espécies $P$. minimum (= P. aleophilum) e Phaeomoniella chlamydospora.

\section{AGRADECIMENTOS}

Os autores agradecem a Prefeitura Municipal da cidade de Louveira, do estado de São Paulo - Brasil, especialmente ao Diretor de Agricultura, Engenheiro Agrícola Daniel Fernando Miqueletto, pelo suporte financeiro dado ao projeto (FUNDAG 1018 - IB-Porta Enxertos).

Os autores expressam, também, agradecimentos a todos os proprietários que gentilmente colaboraram em fornecer plantas da videira Niagara Rosada que apresentavam sintomas e sinais da doença.

Agradecimentos também a Embrapa Uva e Vinho, principalmente nas pessoas do Dr. Lucas da Ressureição Garrido e da analista Renata Gava, por ceder um isolado de Phaeoacremonium spp., que nos auxiliou no levantamento da doença de Petri no estado de São Paulo.

Os autores fazem um agradecimento especial ao Dr. Yodiro Masuda, professor aposentado do Centro de Ciências Agrárias da
UFSCar e já falecido, que contribuiu com valiosas correções e sugestões na dissertação de mestrado da primeira autora do trabalho, facilitando a redação e, consequentemente, a publicação do referido estudo.

\section{REFERÊNCIAS}

1. Abreo, E.; Martínez, S.; Bettucci, L.; Lupo, S. Phaeomoniella chlamydospora and Phaeoacremonium spp. in grapevines from Uruguay. Phytopathologica Mediterranea, Bologna, v. 50, p. S77-S85, 2011.

2. Almança, M. A. K.; Abreu, C. M.; Scopel, F. B.; Benedetti, M.; Halleen, F.; Cavalcanti, F. R. Evidências morfológicas da ocorrência de Phaeomoniella chlamydospora em videiras no estado do Rio Grande do Sul. Bento Gonçalves: Embrapa Uva e Vinho, 2013 (Embrapa Uva e Vinho. Comunicado Técnico 134), $5 \mathrm{p}$.

3. Aroca, A.; Raposo, R. Pathogenicity of Phaeoacremonium species on grapevines. Journal of Phytopathology, Berlin, v. 157, p. 413-419, 2009.

4. Agustí-Brisach, C.; Gramaje, D.; Léon, M.; García-Jiménez, J.; Armengol, J. Evaluation of vineyard weeds as potential hosts of black-foot and Petri disease pathogens. Plant Disease, Saint Paul, v.95, p.803-810, 2011.

5. Back, A. J.; Bruna, E. D.; Dalbó, M. A. Mudanças climáticas e a produção de uva no vale do rio do peixe-SC. Revista Brasileira de Fruticultura, Cruz das Almas, v. 35, n. 1, p. 159-169, 2013. 
6. Bruehl, G. W.; Kaiser, W. J. Some effects of water potential upon endophytic Acremonium spp. in culture. Mycologia, New York, v. 88, p. 809-815, 1996.

7. Conde, C.; Silva, P.; Fontes, N.; Dias, A.C.P.; Tavares, R.M.; Sousa, M.J.; Agasse, A.; Delrot, S.; Gerós, H. Biochemical changes throughout grape Berry development and fruit and wine quality. Food, Kagawa, v. 1, p. 1-22, 2007.

8. Correia, K.C.; Câmara, M.P.S.; Barbosa, M.A.G.; Sales Jr., R.; Agustí-Brisach, C.; Gramaje, D.; Léon, M.; García-Jiménez, J.; Abad-Campos, P.; Armengol, J.; Michereff, S.J. Fungal trunk pathogens associated with table grapes decline in North-eastern Brazil. Phytopathologia Mediterranea, Bologna, v. 52, n. 2, p. 380-387, 2013.

9. Crous, P.W.; Gams, W. Phaeomoniella chlamydospora gen. et comb. nov. a causal organism of Petri grapevine decline and esca. Phytopathologia Mediterrânea, Bologna, v. 39, n. 1, p. 112-118, 2000.

10. De Matheus e Silva, L.F. De celeiro a cenário: Vitivinicultura e turismo na serra gaúcha. GEOUSP - Espaço e Tempo, São Paulo, p. 107-125, 2009.

11. Doyle, J.J.; Doyle, J.L. A rapid DNA isolation procedure for small quan€ tities of fresh leaf tissue. Phytochemical Bulletin, Sussex, v. 19, n. 1, p. 11-15, 1987.

12. Edgar, R.C. MUSCLE: multiple sequence alignment with high accuracy and high throughput. Nucleic Acids Research, Oxford, v. 32, p. 1792 1797, 2004.

13. Fischer, I. H.; Martins, M. C.; Lourenco, S. A.; Kimati, H. \& Amorim, L. Reação de espécies de Passiflora à podridão do colo, causada por Fusarium solani e Phytophthora nicotianae. Fitopatologia Brasileira, Brasília, v. 28, p. 271, 2003.

14. Garrido, L.R.; Sônego, O.R.; Gomes, V.N. Fungos Associados com o Dee clínio e Morte de Videiras no Estado do Rio Grande do Sul. Fitopatologia Brasileira, Brasília, v. 29, n. 3, p. 322-324, 2004.

15. Gatica, M.; Cesari, C.; Magnin, S.; Dupont, J. Phaeoacremonium species and Phaeomoniella chlamydospora in vines showing hoja de malvon and young vine decline symptoms in Argentina. Phytopathologia Mediterranea, Bologna, v. 40, n. 3, p. S317-324, 2001.

16. Glass, N.L.; Donaldson, G.C. Development of primer sets designed for use with the PCR to amplify conserved genes from filamentous ascomycetes. Applied and Environmental Microbiology, Washington, v. 61, p. 1323-1330, 1995.

17. Goodman, L.A. Simultaneous confidence intervals for contrasts among multinomial populations. Annals of Mathematical Statistics, Ann Arbor, v.35, p.716-725, 1964.

18. Goodman, L.A. On simultaneous confidence intervals for multinomial proportions. Technometrics, Washington, v.7, p.247-254, 1965

19. Gramaje, D.; Armengol, J. Fungal trunk pathogens in the grapevine propagation process: potential inoculum sources, detection, identification, and management strategies. Plant Disease, St. Paul, v. 95, n. 9, p. 1040-1055, 2011.

20. Gramaje, D.; Mostert, L.; Groenewald, J.Z.; Crous, P.W. Phaeoacremonium: from esca disease to phaeohyphomycosis. Fungal Biology, Oxford, v. 119 , p. 759-783, 2015.

21. Groenewald, M.; Kang, J-C.; Crous, P.W.; Gams, W. ITS and beta-tubulin phylogeny of Phaeoacremonium and Phaeomoniella species. Mycological Research, Cambridge, v. 105, p. 651-657, 2001.

22. Halleen, F.; Van Niekerk, J.; Mostert, L.; Fourie, P.; Crous, P. Trunk disease pathogens associated with apparently healthy nursey grapevines. Wynboer, p. 12-14, 2005.

23. Halleen, F.; Mostert, L.; Crous, P. Pathogenicity testing of lesser-known vascular fungi of grapevines. Australasian Plant Pathology, Clayton, v. 36, n. 3, p. 277-285, 2007.

24. Mostert, L.; Halleen, F.; Fourie, P.; Crous, P. W. A review of Phaeoacremonium species involved in Petri disease and esca of Grapevines. Phytopathologia Mediterranea, Bologna, v. 45, p. 12-29, 2006.

25. Mugnai, L.; Graniti, A.; Surico, G. Esca (black measles) and brown wood-streaking two old and elusive diseases of grapevine. Plant Disease, St. Paul, v. 83, n. 5, p. 404-417, 1999.

26. O’Donnell, K.; Kistler, H.C.; Cigelnik, E.; Ploetz, R.C. Multiple evolutionary origins of the fungus causing Panama disease of banana: Concordant evidence from nuclear and mitochondrial gene genealogies. Proceedings of the National Academy of Sciences of the United States of America Washington, v. 95, p. 2044-2049, 1998.

27. Petri, L. Osservazioni sopra le alterazioni del legno della vite in seguito a ferrite. Le Stazioni Sperimentali Agrarie Italiane, Modena, v. 45, p. 501-547, 1912.

28. Pinto, P. S. G. C. Doença de Petri da Videira: Avaliação da eficácia de fungicidas na proteção de feridas de poda. $2010.82 \mathrm{f}$. Dissertação (Mestrado em Engenharia Agronômica) - Instituto Superior de Agronomia/ Universidade Técnica de Lisboa. Lisboa, 2010.

29. Queiroz-Voltan, R. B.; Rolim, G. S.; Pedro Júnior, M. J.; Hernandes, J. L. Variações na anatomia foliar de videira Niagara em diferentes sistemas de condução. Bragantia, Campinas, v. 70, n. 3, p. 488-493, 2011.

30. Scheck, H.J.; Vasquez, S.J.; Gubler, W.D. First report of black-foot disease, caused by Cylindrocarpon obtusisporum of grapevine in California. Plant Disease, St. Paul, v. 82, p. 448, 1998.

31. Schmitz, A.; Riesner, D. Purification of nucleic acids by selective precipitation with polyethylene glycol 6000. Analytical Biochemistry, New York, v. 354, p. 311-313, 2006

32. Souza, J.S.I. Uvas para o Brasil. 2 ed. Piracicaba: Fealq. 791 p., 1996.

33. Tamura, K.; Stecher, G.; Peterson, D.; Filipski, A.; Kumar, S. MEGA6: Molecular Evolutionary Genetics Analysis version 6.0. Molecular Biology and Evolution, Chicago, v. 30, p. 2725-2729, 2013.

34. White, T.J.; Bruns, T.; Lee, S.; Taylor, J. Amplification and direct sequencing of fungal ribosomal RNA genes for phylogenetics. In: Innis, M.A.; Gelfand D.H.; Shinsky, J.J.; White, T.J. (Ed.). PCR protocols: a guide to methods and applications. San Diego: Academic, 1990. p. 315322. 